\title{
Electric Vehicle Battery Charger with Improved Power Quality Cuk-Derived PFC Converter
}

\author{
B. R. Ananthapadmanabha, ${ }^{1}$ Rakesh Maurya, ${ }^{1}$ Sabha Raj Arya ${ }^{1}$ \\ and B. Chitti Babu ${ }^{2}$
}

\begin{abstract}
${ }^{1}$ Department of Electrical Engineering, Sardar Vallabhbhai National Institute of Technology, Surat-395007, India

${ }^{2}$ Department of Electrical and Electronics Engineering, University of Nottingham (U.K) Malaysia Campus, 43500-Semenyih, Selangor, Malaysia

E-mail:ananthpbr@gmail.com; rmaurya@eed.svnit.ac.in;sabharaj1@gmail.com; chittibabu.b@nottingham.edu.my
\end{abstract}

Received 1 March 2017; Accepted 21 August 2017;

Publication 11 September 2017

\begin{abstract}
In this paper, an improved power quality converter derived from Cuk converter is proposed for the electric vehicle battery charging under universal-input voltage operation. The proposed converter offers high voltage gain, low voltage stress across the switch, lower conduction losses and reverse recovery losses during low input voltage condition. It yields improvement in efficiency at the low input supply voltage over the single-switch converters such as buck-boost, fly-back, SEPIC, and Cuk topologies and two-switch buck-boost cascaded converters. The proposed converter is designed to operate in a continuous conduction mode. The modeling and simulation of converter are carried out in the Simulink environment of MATLAB software. The developed simulink model is validated by a prototype model of same specification using Xilinx made Spartan3 processor under MATLAB environment in real time. To investigate the performance of the converter in terms of power quality indices like THD, input PF of source voltage and source current are evaluated under constant voltage and constant current modes of battery charging, for
\end{abstract}

Journal of Green Engineering, Vol. 7, 255-284.

doi: 10.13052/jge1904-4720.71211

(c) 2017 River Publishers. All rights reserved. 
wide range of supply voltage variations. The performance of the converter is tested both in steady state and transient conditions.

Keywords: Cuk converter, Continuous Conduction Mode (CCM), Battery charging, Harmonics, Power Factor Correction (PFC).

\section{Introduction}

Power-factor correction (PFC) converters based on non-isolated/isolated DCDC converters have been widely used in electric vehicle battery charger circuits [1]. These converters are designed to operate in continuous or discontinuous conduction mode (CCM or DCM) [2]. The DC-DC converters like boost, buck-boost, and Cuk with discontinuous mode of operation possess power factor correction features [3]. In order to operate PFC converters in DCM, only the DC output voltage needs to be sensed. Although these converters are advantageous to be used in low power applications because of simplicity of control, on contrary they suffer from large current stresses and high conduction loss. A topological review of DC-DC converters (buck, boost, buck-boost, fly-back, forward, Cuk, SEPIC, Zeta converter) under DCM mode is presented in [4]. Based on this review, the boost converter and flyback converter are found to be most suitable for DCM PFC usage. However, remaining DC-DC converters are also employable, if their V-I characteristics are altered to operate in CCM mode.

Large variations in efficiency of the PFC converters have been observed, when fed from wide supply voltage range $(90 \mathrm{~V}-265 \mathrm{~V}, 50 \mathrm{~Hz})$. The boost converter exhibits poor efficiency when fed from low input voltage. In this case conduction loss in the switch and reverse recovery loss in the diode are responsible for poor efficiency at low input voltage. These losses have to be dissipated by providing larger heat sink which leads to low power density. Several topologies of PFC based AC-DC converters have been reported in the literature [1-5]. The losses encountered by the converter when it is fed at lower input voltage can be reduced by employing converters with large step up gain and lower voltage stress across the switch [5].

There are several approaches for providing larger voltage gain and lower voltage stress across the switches. Some of them include transformer based topologies, cascaded converters, quadratic converters, coupled inductor based converters and voltage multipliers. The cascaded converters and quadratic converters can be used to meet desired voltage conversion ratio. However, the overall efficiency of these converters is low due to product of efficiencies of 
each cascaded connected converter. The large turn ratio is necessary for the use of coupled inductor based converters and transformer based topologies. The leakage inductance of these inductors results in increase of voltage spikes across the switch. In addition, it also causes considerable loss [8]. To solve the above issues, clamp circuits and snubber circuits have been proposed in [6-10] which yield additional complexity and cost in the system. The voltage multiplication was carried out utilizing a boost converter for the dual purpose of increased voltage gain and lower switch voltage stress $[11,12]$.

To meet the increasing power demand at higher conversion ratio, various DC-DC converters are integrated with switching capacitor/inductor in [13], which may be operated both for stepping up or down the output voltage. A new group of converters having a single switch, but with large value of voltage gain is proposed in [14]. In comparison with [13], the main features of new family include a higher voltage gain for low duty cycle, and lower voltage stress across the switch. This facilitates the use of switches having low on state resistance, resulting in increased efficiency. The use of schotky diodes was made possible by this configuration which reduced the turn-off losses. Thus, the high voltage gain and lower voltage stress across the switch result in efficiency improvement.

In this paper, Cuk-derived PWM-converter based improved power quality converter is proposed for electric vehicle battery charging applications with universal input $(90 \mathrm{~V}-265 \mathrm{~V})$. The existing power grids may face power quality issues due to off-grid battery charging of more number of electric vehicles $[15,16]$. These power quality issues arise due to harmonics that are drawn by the battery chargers of these electric vehicles. Eventually it degrades the distribution transformer resulting in reduced life [17].

Due to the high voltage gain and low switch voltage stress of the proposed converter, it has reduced conduction and switching losses. The high voltage gain result in lower average current through the switch and thus contributes for lower conduction loss. The reduced voltage stress also contributes for reduction in reverse recovery losses in the output diode, and thus contributing for the overall efficiency improvement. As the topology has inductor at input side the pulsed current problem that is present in buck boost topology is absent. The complete manuscript is organized in eight sections. The brief introduction and issues pertaining to power factor correction is presented in Section 1. In Section 2, the operation of the converter with equivalent circuit under different modes and switching waveforms are described. The design criterion of the converter is provided in Section 3. The brief description of the control scheme, small signal analysis and stability are presented in Section 4. 
The simulation and performance of the converter are discussed in Section 5. Experimental results are discussed in Section 6 and comparative analysis is presented in Section 7. At last, the conclusion is provided in Section 8.

\section{System Cofiguration of Cuk-Derived PFC Converter}

The proposed system configuration derived from the Cuk Converter exhibits different characteristics compared to conventional PFC converters. The switch $\mathrm{SW}_{1}$ of proposed topology is modulated for controlling the output DC voltage or output current. The PFC converter is designed to operate such that current carried by input inductor $\left(L_{i}\right)$ is continuous over one switching cycle. The load is considered as a battery demanding $1.25 \mathrm{~A}$ of current during constant current mode and requiring $400 \mathrm{~V}$ during constant voltage mode. Figure 1a shows the

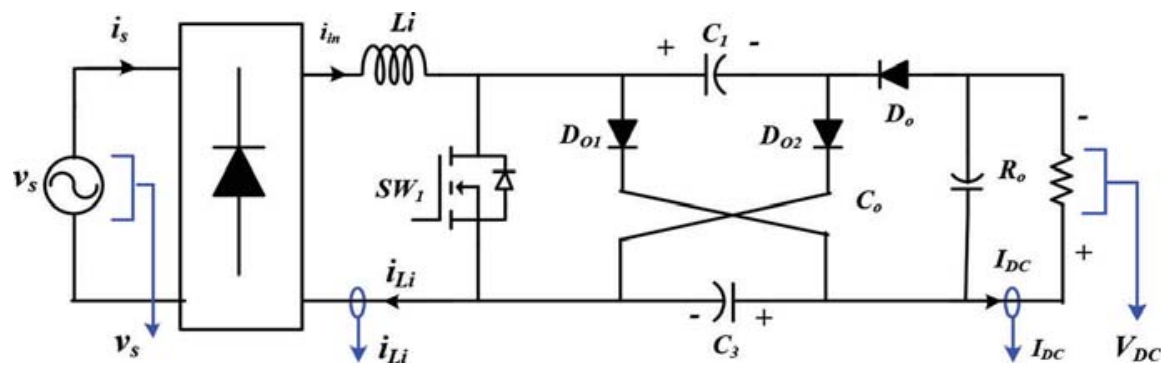

(a)

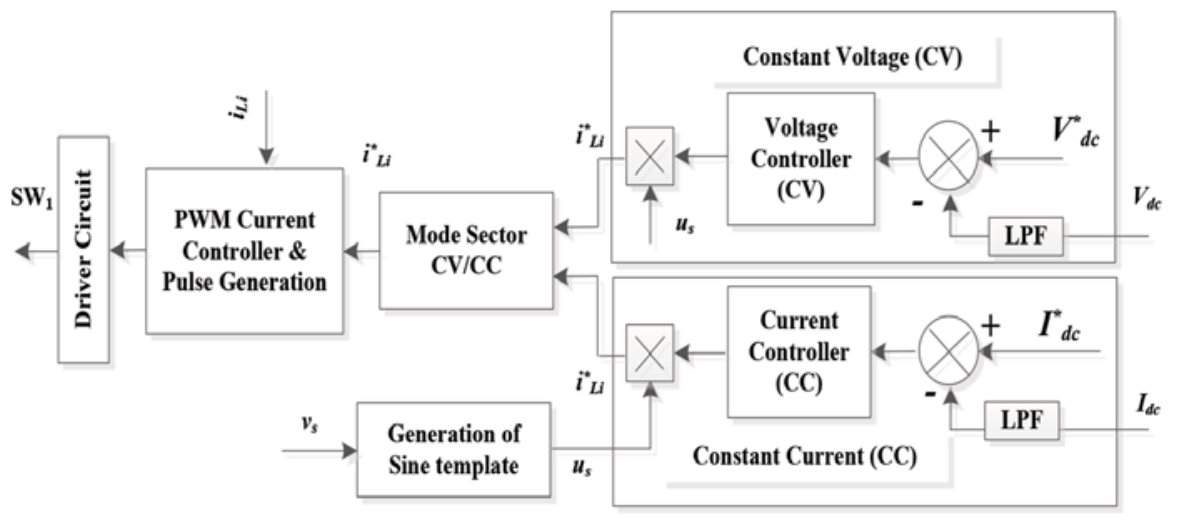

(b)

Figure 1 Schematic diagram of Cuk-derived PFC converter (a) power topology (b) control scheme. 
power circuit of Cuk-derived PFC converter and Figure 1b shows the control scheme for the vehicle battery charging.

The charging cycle of a Li-ion battery (or a similar battery) consists of a constant-current mode and a constant-voltage mode. To reflect these two modes, the design of control block contains two feedback paths as shown in Figure 1b. One feedback path regulates the battery voltage in the constantvoltage mode and second feedback path regulates the battery current in the constant-current mode. The shift between these two modes is implemented using a mode selector block that depends on the state of charge (SOC) of battery.

\subsection{Topology of PFC Converter}

The Cuk-derived PFC converter consists of a single-phase diode bridge rectifier followed by a DC-DC Cuk converter as shown in Figure 1a. It comprises of diodes $\left(\mathrm{D}_{\mathrm{o} 1}, \mathrm{D}_{\mathrm{o} 2}\right)$, input inductor $\left(\mathrm{L}_{\mathrm{i}}\right)$ and intermediate capacitors $\left(\mathrm{C}_{1}, \mathrm{C}_{3}\right)$, as shown in Figure 1a. The output capacitor $\mathrm{C}_{\mathrm{o}}$ provides energy to load during OFF state of switch $\mathrm{SW}_{1}$.

\subsection{Operation of PFC Converter}

The operation of converter depends on switching state of switch $\mathrm{SW}_{1}$. The connection of intermediate capacitors $\left(\mathrm{C}_{1}, \mathrm{C}_{3}\right)$ changes from series to parallel connection as switching state of switch $\mathrm{SW}_{1}$ changes from ON to OFF. The equivalent circuit during $\mathrm{ON}$ and $\mathrm{OFF}$ state of the switch $\mathrm{SW}_{1}$ are depicted in Figure $2 \mathrm{a}$ and Figure $2 \mathrm{~b}$. The Cuk-derived PFC converter is designed to operate in continuous conduction mode i.e. the current through inductor $\left(\mathrm{i}_{\mathrm{Li}}\right)$ is continuous over one switching period. Figure $2 \mathrm{c}$ shows the voltage and current waveforms over one switching cycle. The detailed mode-wise analysis is carried out with assumptions that all the circuit elements are ideal. The output filter capacitor $\left(\mathrm{C}_{\mathrm{o}}\right)$ is assumed to be large such that the output voltage ripple is neglected.

Mode I: When the switch $\mathrm{SW}_{1}$ is turned $\mathrm{ON}$, the output diode $\mathrm{D}_{\mathrm{O}}$ is forward biased. Power diodes $\left(\mathrm{D}_{\mathrm{o} 1}, \mathrm{D}_{\mathrm{o} 2}\right)$ are in reversed biased by the negative voltage $\left(\mathrm{V}_{\mathrm{C} 1}+\mathrm{V}_{\mathrm{dc}}\right)$ that appears across them. The equivalent circuit during this mode is shown in Figure 2a. During this mode, the input inductor current $\left(\mathrm{i}_{\mathrm{Li}}\right)$ increases gradually from its minimum value $\left(\mathrm{I}_{\mathrm{Lmin}}\right)$ and stores energy as shown in Figure 2c. The intermediate capacitors $\left(\mathrm{C}_{1}, \mathrm{C}_{3}\right)$ start discharging in series through path indicated in Figure $2 \mathrm{a}$ and charges the output capacitor as 


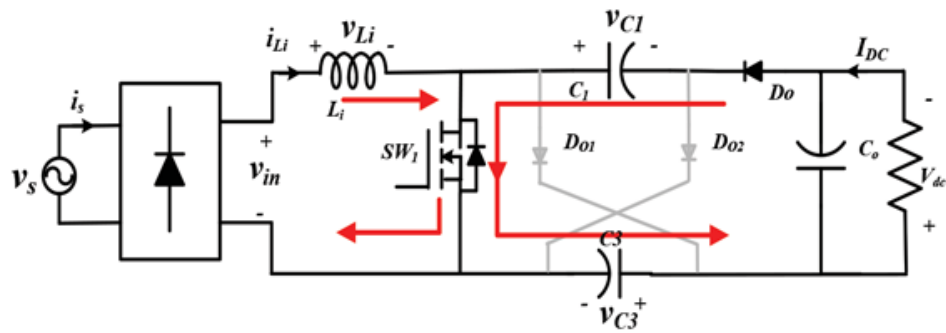

(a)

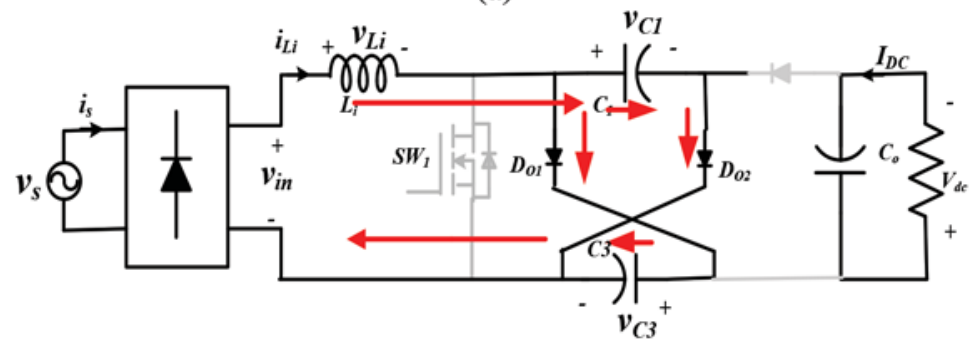

(b)

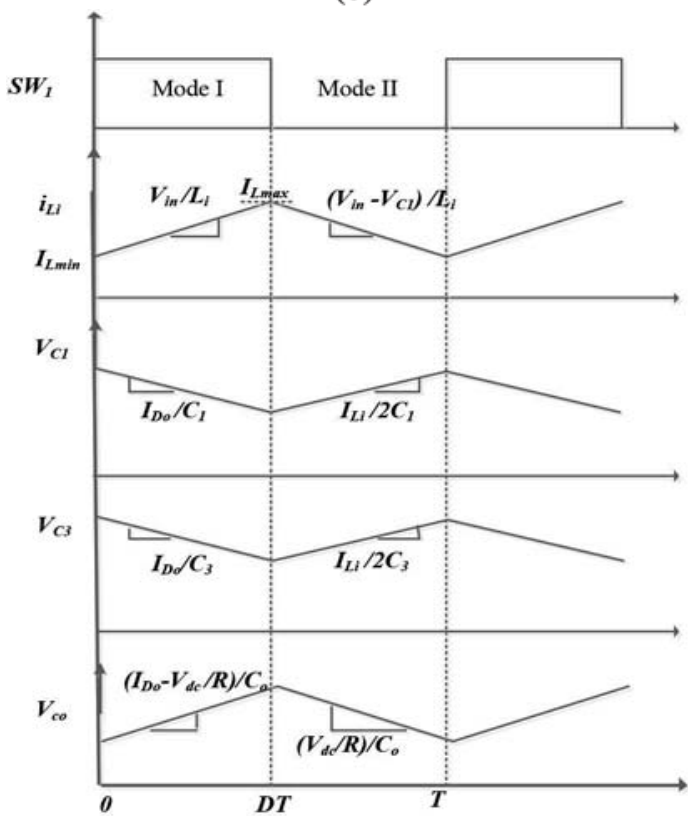

(c)

Figure 2 Equivalent circuit during operating modes over one switching cycle (a) mode-I (b) mode-II (c) voltage and current waveforms during switching. 
shown in Figure 2c. At the end of the mode-I, inductor current reaches to its maximum value ( $\mathrm{i}_{\mathrm{Lmax}}$ ) as shown in Figure $2 \mathrm{c}$.

Mode II: This mode start with the turning OFF of the switch $\mathrm{SW}_{1}$. The equivalent circuit is depicted in Figure 2b. In this mode of operation both power diodes $\left(\mathrm{D}_{\mathrm{o} 1}, \mathrm{D}_{\mathrm{o} 2}\right)$ are in forward biased at the same time, which gives rise to a path for inductor current. The output diode $\mathrm{D}_{\mathrm{O}}$ is reversed biased by the negative voltage $\left(\mathrm{V}_{\mathrm{C} 1}-\mathrm{V}_{\mathrm{o}}\right)$. In this interval, the input inductor current charges both capacitors $\mathrm{C}_{1}$ and $\mathrm{C}_{3}$. Simultaneously, output capacitor $\mathrm{C}_{\mathrm{o}}$ discharges energy by supplying power to load as shown in Figure $2 \mathrm{~b}$.

\section{Design of Cuk-Derived PWM Converter}

The design of Cuk-derived PWM converter mainly includes the calculation of passive components. The value of these components depend on power requirement, switching frequency, worst case input and output voltage requirements, mode of operation and loading conditions. A Cuk-derived PWM converter is designed for DC-link voltage control and PFC at the AC mains. The instantaneous supply voltage is given as, $v_{s}(t)=V_{m} \sin \left(2 \pi f_{L}\right) t=$ $230 \sqrt{2} \sin (314 t) V$; where $V_{m}$ is the peak input voltage, and $f_{L}$ is the supply frequency.

The instantaneous voltage appearing after the diode bridge rectifier is as follows,

$$
v_{\text {in }}(t)=\left|V_{m} \sin \left(2 \pi f_{L}\right) t\right|=|230 \sqrt{2} \sin (314 t)| V
$$

The output DC voltage of Cuk-derived PWM converter is given as,

$$
V_{d c}=\frac{2}{1-D} v_{i n}
$$

The momentary value of duty cycle $D(t)$ depends on the input voltage for the PFC converter, $v_{i n}(t)$ and the required output voltage $V_{d c}$.

$$
D=\frac{V_{d c}-2 v_{i n}}{V_{d c}}
$$

The value of input inductor $\left(\mathrm{L}_{\mathrm{i}}\right)$ is determined by allowing the ripple current to be $25 \%$ of the average value of the current. The value of intermediate capacitors $\left(\mathrm{C}_{1}, \mathrm{C}_{3}\right)$ is calculated with an accepted voltage ripple factor of $10 \%$. Allowable ripple in output voltage assumed as $4 \%$ of $V_{d c}$ for calculating the value of output capacitor. 


\section{Control Scheme and Small Signal Model}

Battery charging methods namely constant voltage and constant current charging are implemented. Depending on mode of battery charging, either regulated output voltage or output current is to be maintained with unity power factor at the ac input supply side. A brief description of the control scheme and stability are presented in this section.

\subsection{Control Scheme}

The main objective of the controller of the proposed converter is to maintain voltage or current regulation at output dc side and harmonic reduction at the ac supply input. The control structure is shown in Figure 1b. The sensed voltage or current at the point of DC output terminal contains distorted components due to high frequency switching. Therefore, these sensed signals are passed through low pass filters (LPFs) and these filtered signals are used as input signals to controller.

The reference voltage $V_{d c}^{*}(k)$ is compared with the sensed dc-link voltage $V_{d c}(k)$ to generate a voltage error $V_{e}(k)$, where voltage error $V_{e}(k)$ at any instant ' $k$ ' is given as

$$
V_{e}(k)=V_{d c}^{*}(k)-V_{d c}(k)
$$

This voltage error $V_{e}(k)$ is fed to proportional-integral (PI) controller for generation of a controlled output $V_{c}(k)$ as

$$
V_{c}(k)=V_{c}(k-1)+k_{p v}\left\{V_{e}(k)-V_{e}(k-1)\right\}+k_{i v} V_{e}(k)
$$

Where, $k_{p v}, k_{i v}$ are the proportional gain and integral gain of the voltage PI controller.

The reference current $i_{L i}^{*}(k)$ is generated by multiplying the controller output with the unit template of supply voltage $u_{s}(k)$ as follows;

$$
u_{s}(k)=\left|\frac{v_{s}(k)}{V_{m}}\right| ; \quad i_{L i}^{*}(k)=u_{s} V_{c}(k) ; \quad i_{L i}^{*}(k)=u_{s} I_{c}(k)
$$

Where $u_{s}(k)$ is the unit template of supply voltage; $v_{s}(k)$ represents the amplitude of supply voltage at any instant $k$. This reference current $i_{L i}^{*}(k)$ is compared with the sensed input current $i_{L i}(k)$ to generate the PWM signal

for PFC converter switch. Based on state of battery charge, the selection of constant current $(\mathrm{CC})$ or constant voltage $(\mathrm{CV})$ mode is carried out.

From Mode-I and Mode-II operation of the converter, two sets of differential equations describing each mode of the converter leads to the development 
of the state space model of the system. Further state space averaging of the two state space model results in an averaged model given by Equation (7).

$$
\begin{aligned}
& \frac{d x_{o}}{d t}=M x_{o}(t)+N u_{o}(t): y_{o}(t)=O x_{o}(t)+P u_{o}(t): \\
& M=M_{1} d(t)+M_{2}(1-d(t)): \\
& N=N_{1} d(t)+N_{2}(1-d(t)): \\
& O=O_{1} d(t)+O_{2}(1-d(t)): \\
& P=P_{1} d(t)+P_{2}(1-d(t)):
\end{aligned}
$$

Which is a nonlinear continuous time equation.

To obtain a small signal model around the quiescent operating point, the following small signal perturbation is added to the above averaged model

$$
\begin{gathered}
x_{o}(t)=X_{o}+\hat{x_{o}(t)}: y_{o}(t)=Y_{o}+\hat{y_{o}(t)}: u_{o}(t)=U_{o}+u_{o}(t) \\
: d(t)=D+\hat{d(t)}
\end{gathered}
$$

Where Xo $>>x_{o}(t):$ Yo $>>y_{\mathrm{o}}(t):$ Uo $>>u_{\mathrm{o}}(t): \mathrm{D}>>d \hat{(t)}$ :

Adding the above perturbations in the averaged model, we get following small signal model,

$$
\begin{aligned}
& \frac{d x_{O}(t)}{d t}=M \hat{x_{O}(t)}+N \hat{u_{O}(t)}+N_{d} \hat{d(t)}: \\
& y_{O}(t)=O \hat{x_{O}(t)}+P \hat{u_{O}(t)}+P_{d} \hat{d(t)}:
\end{aligned}
$$

Where

$$
\begin{aligned}
& N_{d}=\left(M_{1}-M_{2}\right) X_{O}+\left(N_{1}-N_{2}\right) U_{O} \\
& P_{d}=\left(O_{1}-O_{2}\right) X_{O}+\left(P_{1}-P_{2}\right) U_{O}
\end{aligned}
$$

Taking Laplace transform and simplifying

$$
\begin{aligned}
& X_{O}(s)=(s I-M)^{-1}\left[N u_{O} \hat{(s)}+N_{d} \hat{d}(s)\right] \\
& \hat{Y_{O}} \hat{(s)}=O(s I-M)^{-1}\left[N u_{O} \hat{(s)}+N_{d} \hat{d}(s)\right]+P u_{O} \hat{(s)}+P_{d} \hat{d}(s)
\end{aligned}
$$

Using the above equation for output, the duty-cycle-to-output, duty-cycle to inductor current and input-to-output transfer function is given by

$$
\frac{\hat{v_{D C}}(s)}{\hat{d(s)}}=O(s I-M)^{-1} N_{d}+P_{d}
$$




$$
\begin{aligned}
& \frac{\hat{i_{L}(s)}}{\hat{\wedge}}=O(s I-M)^{-1} N_{d}+P_{d} \\
& d(s) \\
& \frac{\hat{v_{D C}}(s)}{\hat{\wedge}}=O(s I-M)^{-1} N+P \\
& v_{i n}(s)
\end{aligned}
$$

In this paper, Leverrier algorithm is used to develop the resolvent matrix $(s I-M)^{-1}$.

The transfer functions from Equation (9) and Equation (10) are written as,

$$
\begin{aligned}
& \frac{v_{D C}(s)}{d(s)}=\frac{4 V_{i n} D\left[s R C_{1}+2 D\right]}{\left[8 R C_{o} C_{1} L_{i} s^{3}+8 C_{1} L_{i} s^{2}+4 R C_{o} D_{1}^{2} s+3 D_{1}^{2}+3 D_{1}^{2}\right.} \\
& \frac{i_{L i}(s)}{d(s)}=\frac{16 V_{i n}\left[R C_{o}(2-D) s+D\right]}{D_{1}\left[8 R^{2} C_{o} C_{1} L_{i} s^{3}+8 C_{1} L_{i} R s^{2}+4 R^{2} C_{o} D_{1}^{2} s+3 D_{1}^{2} D^{2} R+3 D_{1}^{2} R\right]}
\end{aligned}
$$

The block diagram describing the closed loop current mode control is given by Figure 3 .

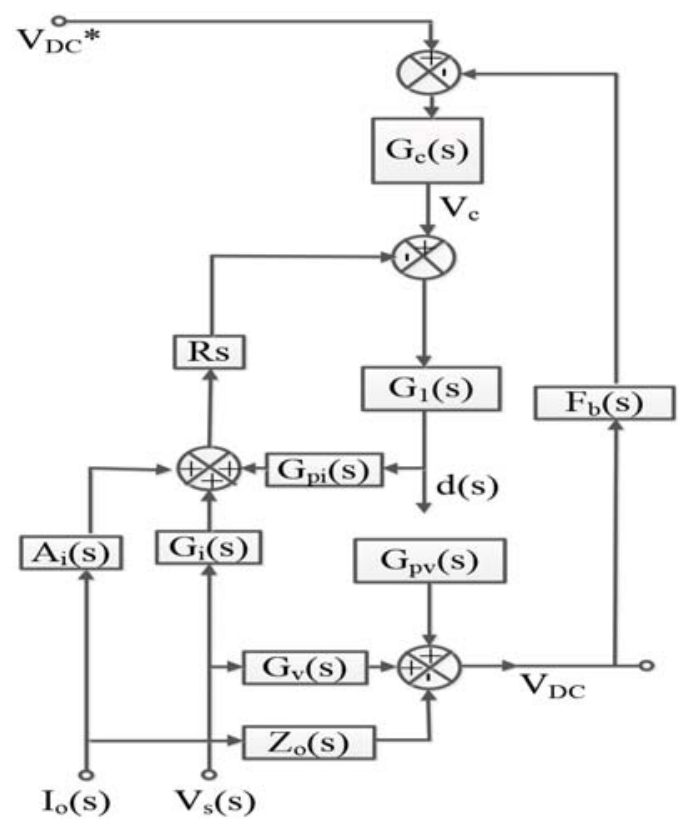

Figure 3 Block Diagram of current mode controlled converter. 
Where,

$\mathrm{G}_{\mathrm{pv}}(\mathrm{s})$ is the duty-cycle to output voltage transfer function given by Equation (9)

$\mathrm{G}_{\mathrm{pi}}(\mathrm{s})$ is the duty-cycle to inductor current transfer function given by Equation (10)

$\mathrm{G}_{1}(\mathrm{~s})$ is called the current error to duty cycle transfer function given by,

$$
G_{1}(s)=\frac{12 f_{s}^{2}}{R_{s} G_{P i} s\left(s+w_{s h}\right)}
$$

Where $w_{s h}=\frac{(1-a) \cdot 6 \cdot f_{\mathrm{s}}}{1+a}, a=\frac{\alpha 2-\alpha 3}{\alpha 1+\alpha 3}, \alpha_{1}$ is the on-time slope of inductor current, $\alpha_{2}$ is the off-time slope of inductor current and $\alpha 3$ is the slope of the external compensating ramp.

$\alpha_{1}$ and $\alpha_{2}$ are given by equations: $\alpha_{1}=V_{i n} / D ; \alpha_{2}=\left(V_{o}\right) /(1-D)$.

The control voltage to duty-cycle transfer function $G_{d}(s)$ generated by the internal current loop is given by following equation,

$G_{d}(s)=\frac{d(s)}{v_{c}(s)}=\frac{G_{1}(s)}{1+G_{1}(s) \cdot G_{P i}(s) \cdot R_{s}}=\frac{12 \cdot f_{s}^{2}}{R_{s} \cdot G_{P i}(s) \cdot\left(s^{2}+s w_{s h}+12 f_{s}^{2}\right)}$

The other transfer functions in the block diagram are,

$\mathrm{G}_{\mathrm{C}}(\mathrm{s})$ is the transfer function of the compensator.

$\mathrm{A}_{\mathrm{i}}(\mathrm{s})$ is the input voltage to inductor current transfer function.

$\mathrm{G}_{\mathrm{i}}(\mathrm{s})$ is output current to inductor current transfer function.

$\mathrm{Z}_{\mathrm{O}}(\mathrm{s})$ is the output impedance.

$\mathrm{G}_{\mathrm{v}}(\mathrm{s})$ is the audio susceptibility.

The change in input and output voltage is assumed to be negligible over a switching cycle neglecting the feed-forward gains.

Thus the compensator transfer function $\mathrm{G}_{\mathrm{c}}(\mathrm{s})$ is designed based on the open loop gain given by $\mathrm{G}_{\mathrm{c}}(\mathrm{s}) \cdot \mathrm{G}_{\mathrm{d}}(\mathrm{s}) \cdot \mathrm{G}_{\mathrm{pv}}(\mathrm{s}) \cdot \mathrm{F}_{\mathrm{b}}(\mathrm{s})$. Considering a unity feedback system, the open loop gain is given by $\mathrm{G}_{\mathrm{c}}(\mathrm{s}) \cdot \mathrm{G}_{\mathrm{d}}(\mathrm{s}) \cdot \mathrm{G}_{\mathrm{pv}}(\mathrm{s})$. The root locus is plotted for this open loop transfer function and a PI controller with one pole at origin and a zero is added to make the transfer function stable by drawing the plot towards the left of s plane as shown in Figure 4. The zeros which are going towards the right half plane are pulled towards the right by the right position of the presence of zero of the PI controller. It is observed that there are 3 poles heighted indicating a 3 rd order system. 


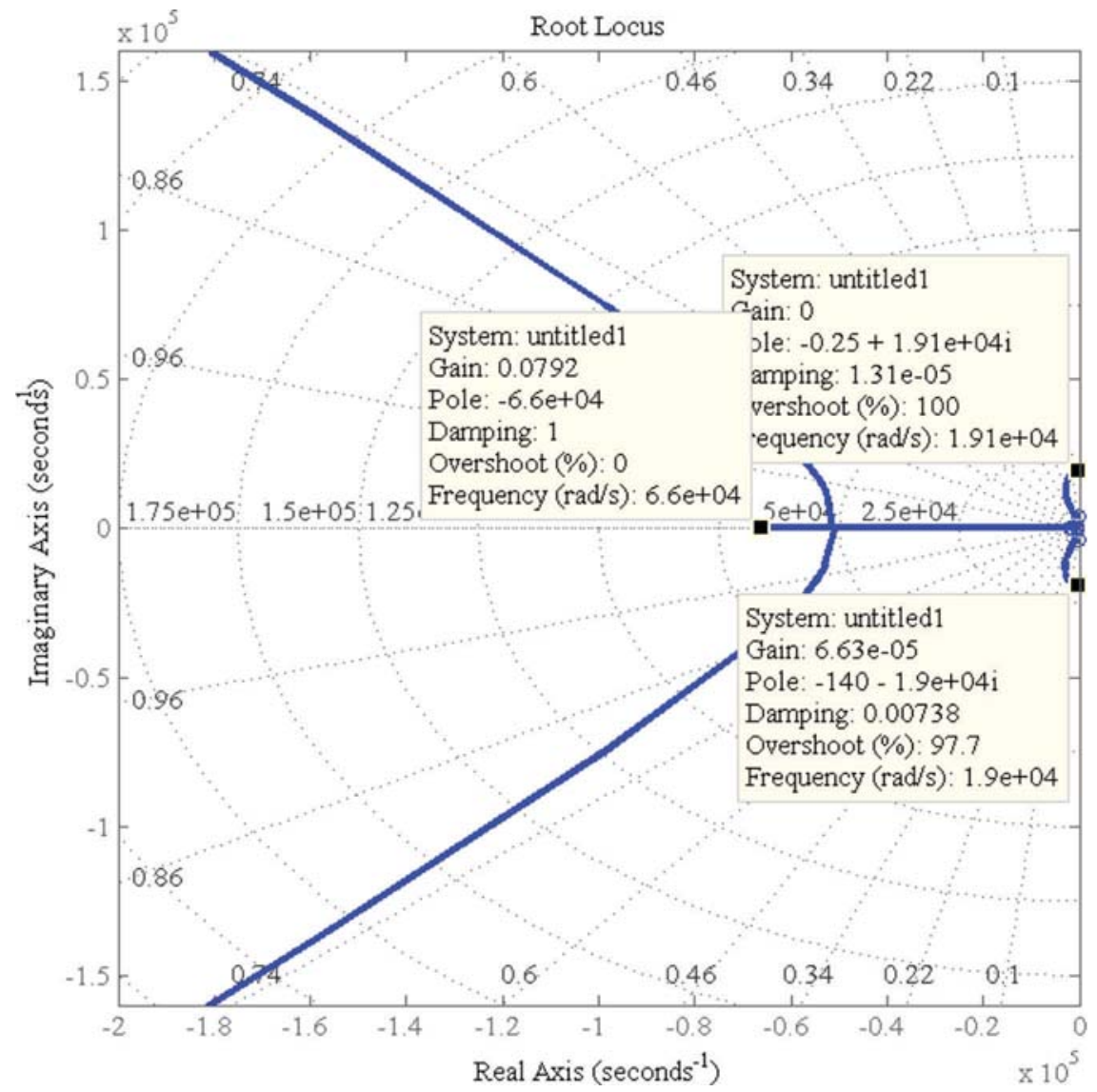

Figure 4 Root Locus of the open loop transfer function of the converter considering current mode control.

\section{Performance of Proposed Converter}

Simulink model of Cuk-derived PWM-Converter-based IPQC, rated for $500 \mathrm{~W}, 400 \mathrm{~V} / 1.25 \mathrm{~A}$ is developed with the help of SIM Power System toolbox of MATLAB software. The parameters of the simulation are tabulated in Appendix A. The performance of the converter feeding the resistive load is simulated for continuous current mode. Input voltage $\left(v_{S}\right)$ and input current $\left(i_{S}\right)$ are used for assessing the power quality of the converter. The voltage $\left(V_{d c}\right)$ across the DC Link, the current through the input inductor $\left(i_{L i}\right)$, the voltage across the intermediate capacitor $\left(V_{C 1}, V_{C 3}\right)$, voltage across 
the switch $\left(V_{S W 1}\right)$, and switch current $\left(i_{S W 1}\right)$ are observed during simulation study. From the above observed parameters, power quality parameters are obtained for further evaluation of its quality.

\subsection{Steady State Performance of Cuk-Derived PWM Converter Feeding the Battery Load in Constant Current Mode}

Figure 5a shows the steady state performance of the converter with $230 \mathrm{~V}$, $50 \mathrm{~Hz}$ supply input and a 12.5 Ah battery load. As shown in Figure 5a, unity power factor is maintained with absence of phase delay between voltage and current in addition to maintenance of shape of the current waveform. The output current regulation at $1.25 \mathrm{~A}$ is observed, with disturbances in action. Continuous increase in battery voltage is observed. The current and voltage stress of the different components are noted helping us in selection of proper ratings. A CCM mode of operation is observed for the input inductor as per the design. A switch voltage stress of $375 \mathrm{~V}$ and switch current stress of $10 \mathrm{~A}$ is observed.

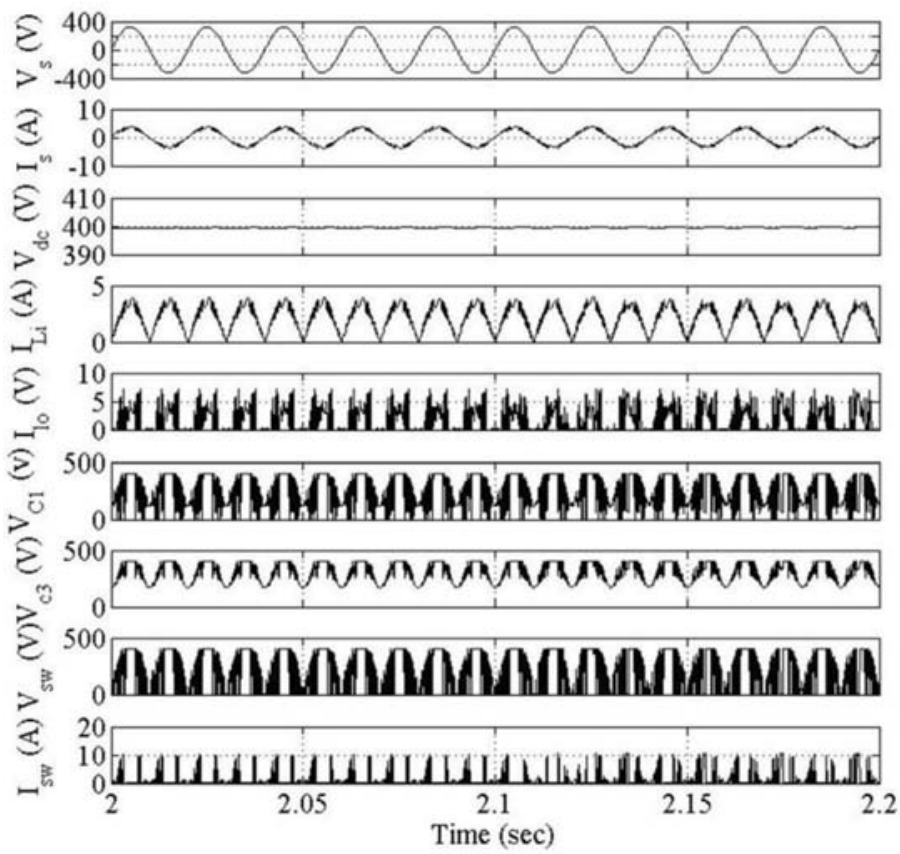

(a) 


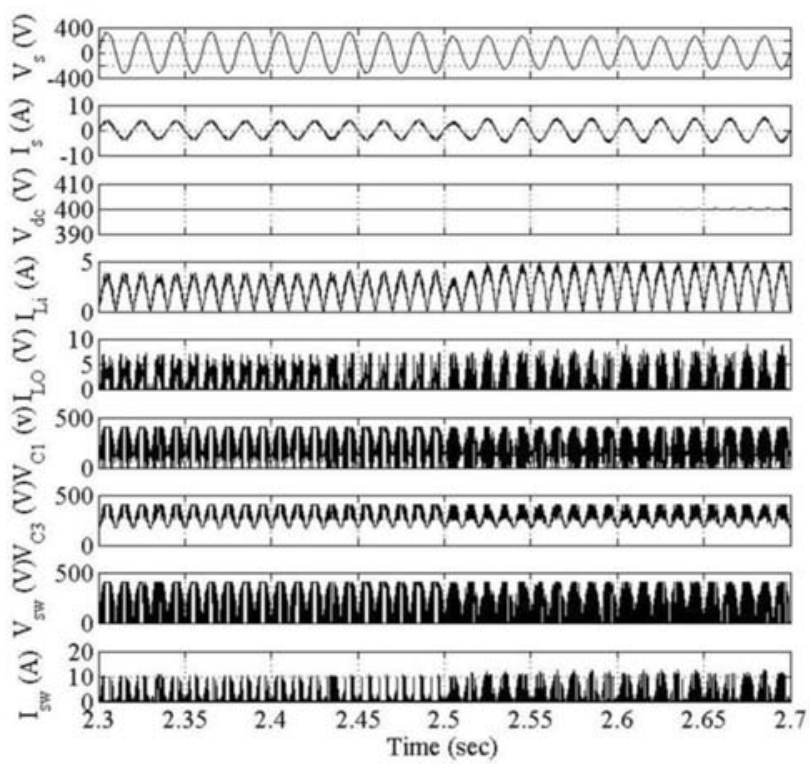

(b)

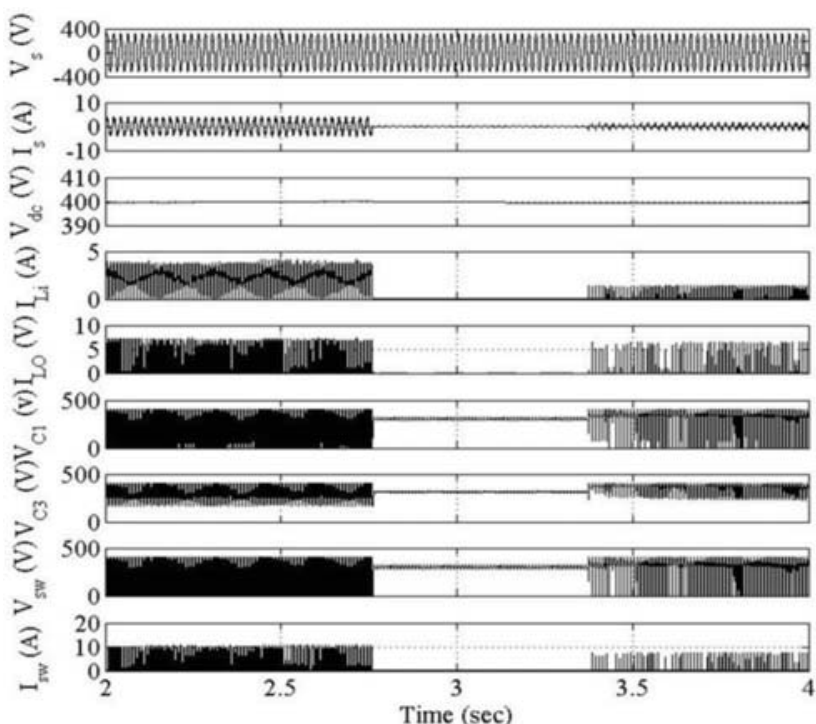

(c)

Figure 5 Simulation results (a) Steady state performance at $230 \mathrm{~V}$ input in CC Mode (b) Dynamic response during CC Mode under a supply voltage change from $230 \mathrm{~V}$ to $180 \mathrm{~V}$ (c) Dynamic performance with an input of $230 \mathrm{~V}$ under a mode change from $\mathrm{CC}$ to $\mathrm{CV}$. 


\subsection{Transient Performance of Cuk-Derived PWM Converter Feeding the Battery Load under Source Voltage Disturbance During CC Mode}

To study the converter performance against source voltage variation, certain disturbances in source voltage from its nominal voltage $230 \mathrm{~V}$ are applied, and its response against these variations is observed. In Figure 5b, a $20 \%$ step decrease in source voltage from its nominal value of $230 \mathrm{~V}$ is applied at time instant $t=1 \mathrm{sec}$. It is observed that, output current regulation is maintained. It is observed that the overshoot, undershoot and transient response time are within limits.

\subsection{Transient Performance of Cuk-Derived PWM Converter Feeding the Battery Load under Transition from CC to $\mathrm{CV}$}

Figure $5 \mathrm{c}$ shows transient response of converter with transition from $\mathrm{CC}$ to $\mathrm{CV}$ at a source voltage of $230 \mathrm{~V}$. It is observed that DC output current of $1.25 \mathrm{~A}$ is obtained during CC Mode and an output voltage of $400 \mathrm{~V}$ is obtained during $\mathrm{CV}$ Mode. In both of these modes, source voltage $\left(v_{S}\right)$ and current $\left(i_{S}\right)$ are in phase. At time instant $t=2.7 \mathrm{sec}$, transition from $\mathrm{CC}$ to $\mathrm{CV}$ occurs as the battery reaches a voltage of $400 \mathrm{~V}$. It is observed that inductor current waveform is continuous during $\mathrm{CC}$ mode and discontinuous during CV Mode. Because of the DCM mode of operation THD of current is high initially and later settles to a low value after a transient time.

\subsection{THD of Input Voltage and Input Current of Cuk-Derived PWM Converter Feeding Battery Load at $230 \mathrm{~V}$ Input in CV Mode and CC Mode}

The input voltage and current along with its spectra and THD are observed. Figure $6 \mathrm{a}$ and Figure $6 \mathrm{~b}$ show the input voltage THD at $230 \mathrm{~V}$ with battery load. The results are obtained both in CV and CC modes. Figure $6 \mathrm{c}$ and Figure $6 \mathrm{~d}$ show the THD of the input current at an input of $230 \mathrm{~V}$ and battery load in CV mode and CC mode respectively. Table 1 shows tabular column listing voltage THD, current THD and total power factor in CV mode and CC mode respectively. 

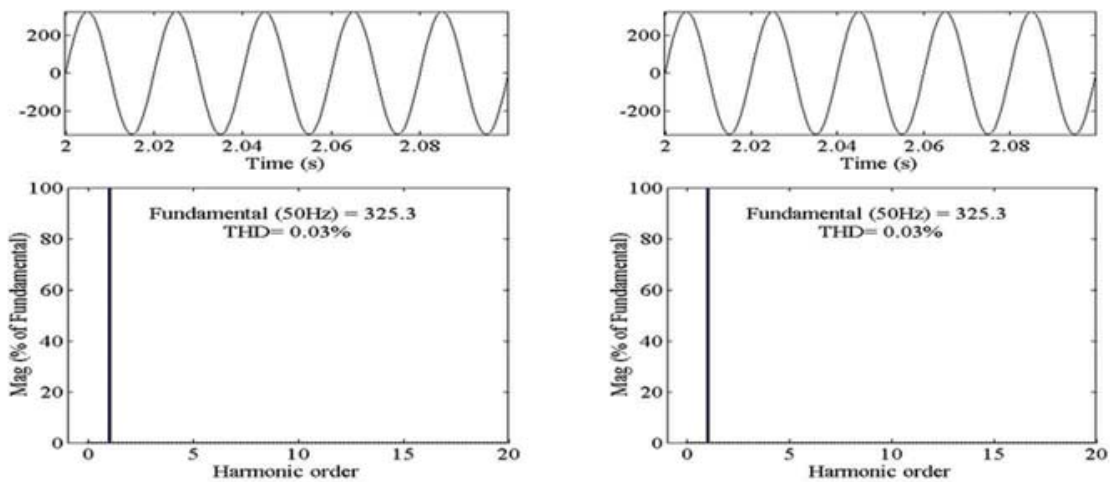

(a)

(b)
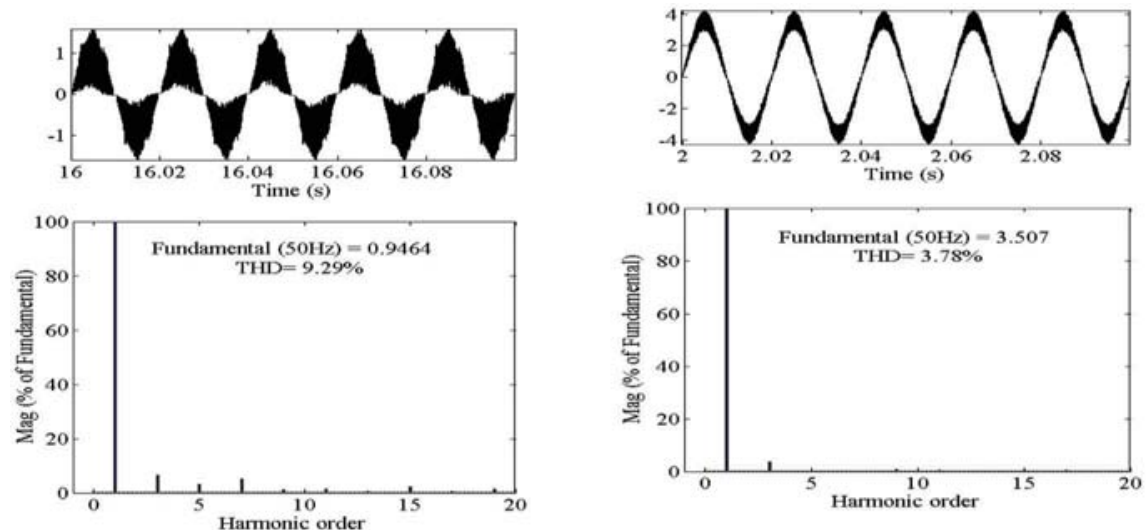

(c)

(d)

Figure 6 Harmonics spectra of input voltage and current with an input of $230 \mathrm{~V}$ in (a) CV Mode (b) CC Mode (c) CV Mode (d) in CC Mode.

Table 1 Performance of converter in CV and CC mode during supply voltage variation

\begin{tabular}{|c|c|c|c|c|c|c|c|}
\hline \multirow[b]{3}{*}{ Sr. No. } & \multirow{3}{*}{$\begin{array}{c}\text { Supply } \\
\text { Voltage } \\
\left(V_{\mathrm{s}}\right)\end{array}$} & \multicolumn{6}{|c|}{ System Feeding Resistive Load of $500 \mathrm{~W}$} \\
\hline & & \multicolumn{3}{|c|}{ (in CV Mode) } & \multicolumn{3}{|c|}{ (in CC Mode) } \\
\hline & & $V_{\mathrm{STHD}}$ & $I_{\mathrm{STHD}}$ & $\mathrm{PF}$ & $V_{\text {sTHD }}$ & $I_{\mathrm{STHD}}$ & $\mathrm{PF}$ \\
\hline 1 & 90 & $0.56 \%$ & $9.9 \%$ & 0.99 & $0.3 \%$ & $2.91 \%$ & 0.99 \\
\hline 2 & 120 & $0.23 \%$ & $9.40 \%$ & 0.99 & $0.14 \%$ & $2.41 \%$ & 0.99 \\
\hline 3 & 150 & $0.15 \%$ & $10.16 \%$ & 0.99 & $0.05 \%$ & $2.32 \%$ & 0.99 \\
\hline 4 & 200 & $0.09 \%$ & $9.2 \%$ & 0.99 & $0.03 \%$ & $3.09 \%$ & 0.99 \\
\hline 5 & 230 & $0.06 \%$ & $9.27 \%$ & 0.99 & $0.03 \%$ & $4.05 \%$ & 0.99 \\
\hline 6 & 265 & $0.05 \%$ & $9.85 \%$ & 0.99 & $0.03 \%$ & $4.05 \%$ & 0.99 \\
\hline
\end{tabular}




\section{Experimental Analysis}

The proposed converter is developed in the laboratory environment with the parameters given in Appendix B to validate the simulation study. A non-ideal supply system is realized by inserting additional source inductance for voltage distortion. A Fluke power analyzer and Agilent make digital oscilloscope are used for recording of waveforms in steady state and transient state respectively. The proposed converter is implemented using the Xilinx made Spartan3 FPGA board (XC3S5000) with $25 \mu$ s sampling time in real time. Available slots has $\mathrm{ADC}$ and signal conditioning blocks with a finite number of channels allocated for each block. The experimental set up is shown in Figure 7. The input source voltage $\left(v_{\mathrm{S}}\right)$, source current $\left(\mathrm{i}_{\mathrm{s}}\right)$, DC output voltage $\left(\mathrm{V}_{\mathrm{DC}}\right)$, DC output current $\left(\mathrm{I}_{\mathrm{DC}}\right)$, switch voltage $\left(\mathrm{v}_{\mathrm{SW}}\right)$, switch current $\left(\mathrm{i}_{\mathrm{SW}}\right)$ are recorded as shown in Figure 8-Figure 9. The performance of the converter is studied for battery charging application in constant voltage and constant current mode.

Figure 8 shows steady state response of converter with battery charging application at different input voltage, at $85 \mathrm{~V}$ and $230 \mathrm{~V}$. It is observed that constant $400 \mathrm{~V}$, DC output voltage is obtained and at the same time input source voltage (vs) and current (is) are in phase. The experimental results of Figure 8a to Figure $8 \mathrm{~b}$ show voltage and current waveforms at ac supply side and battery side whereas second image of aforesaid figures represent the inductor current $\left(i_{L i}\right)$, voltage stress $\left(v_{S W 1}\right)$ and current stresses $\left(i_{S W 1}\right)$ of switch SW1, both taken during constant voltage charging mode. A battery load to be charged at $500 \mathrm{~W}$ is connected and converter performances are evaluated. With wide range of ac supply voltage ( $85 \mathrm{~V}$ to $265 \mathrm{~V}$ ), constant DC voltage of $400 \mathrm{~V}$ is

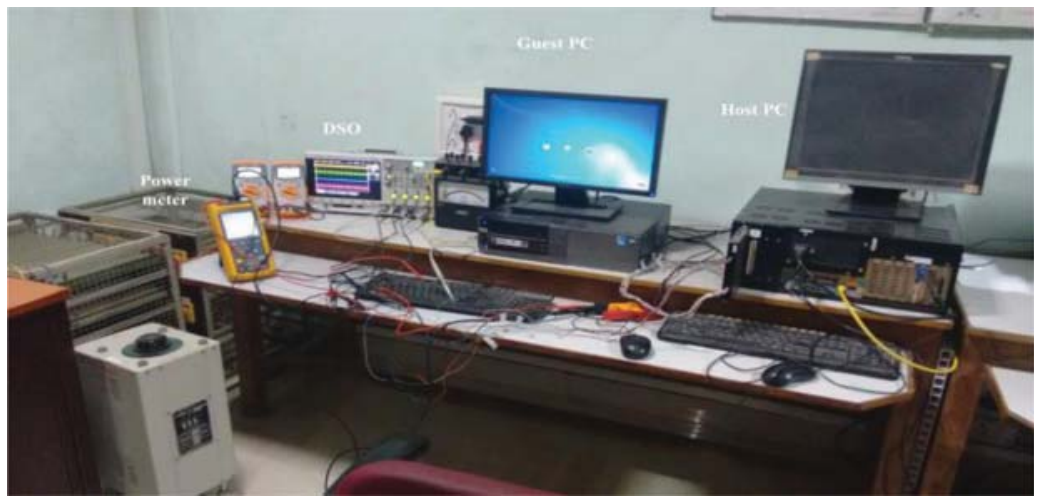

Figure 7 Experimental setup of prototype model. 


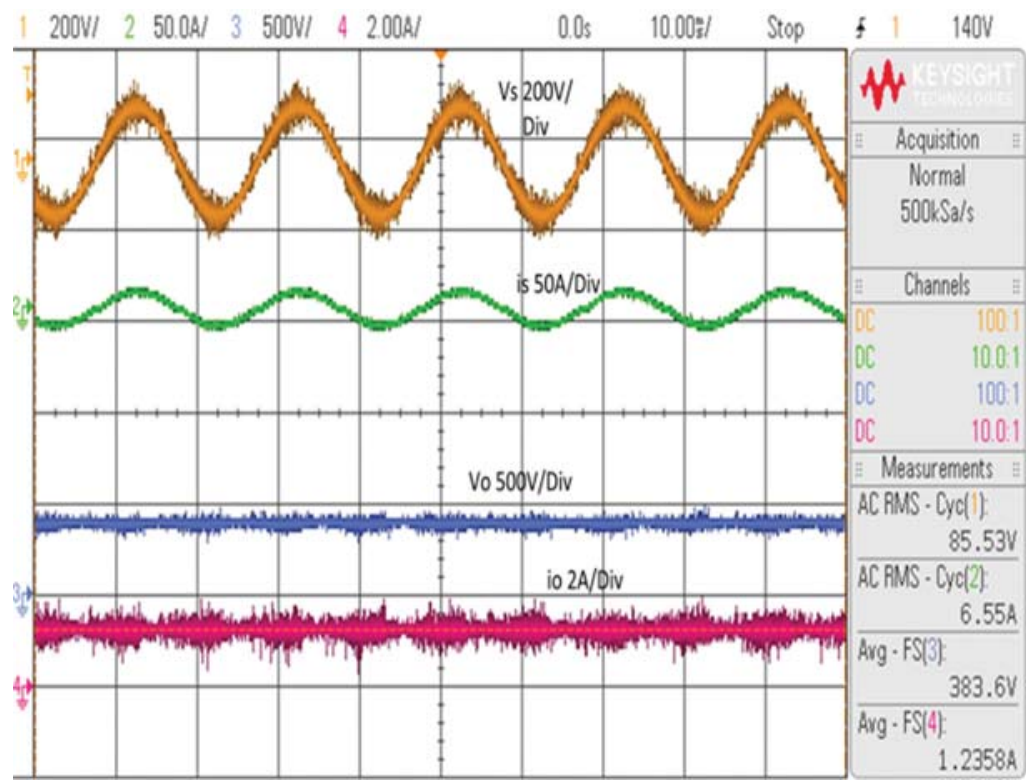

(i) $\left(\mathrm{Ch}-1: \mathrm{v}_{\mathrm{s}}(200 \mathrm{~V} / \mathrm{div}), \mathrm{Ch}-2: \mathrm{i}_{\mathrm{s}}(50 \mathrm{~A} / \mathrm{div}), \mathrm{Ch}-3: \mathrm{v}_{\mathrm{o}}(500 \mathrm{~V} / \mathrm{div}), \mathrm{Ch}-4: \mathrm{i}_{\mathrm{o}}(2 \mathrm{~A} / \mathrm{div})\right.$

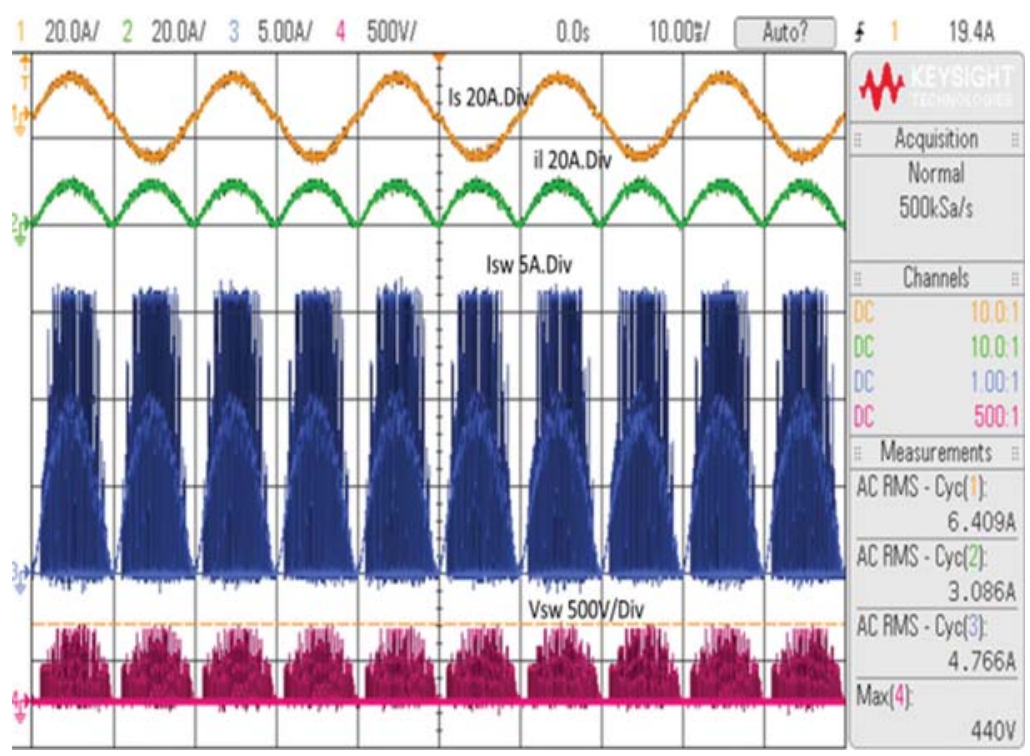

(ii) Ch-1: $\mathrm{i}_{\mathrm{s}}(20 \mathrm{~A} / \mathrm{div}), \mathrm{Ch}-2: \mathrm{i}_{\mathrm{L}}(20 \mathrm{~A} / \mathrm{div}), \mathrm{Ch}-3: \mathrm{i}_{\mathrm{sw}}(5 \mathrm{~A} / \mathrm{div}), \mathrm{Ch}-4: \mathrm{v}_{\mathrm{sw}}(500 \mathrm{~V} / \mathrm{div})$

(a) 


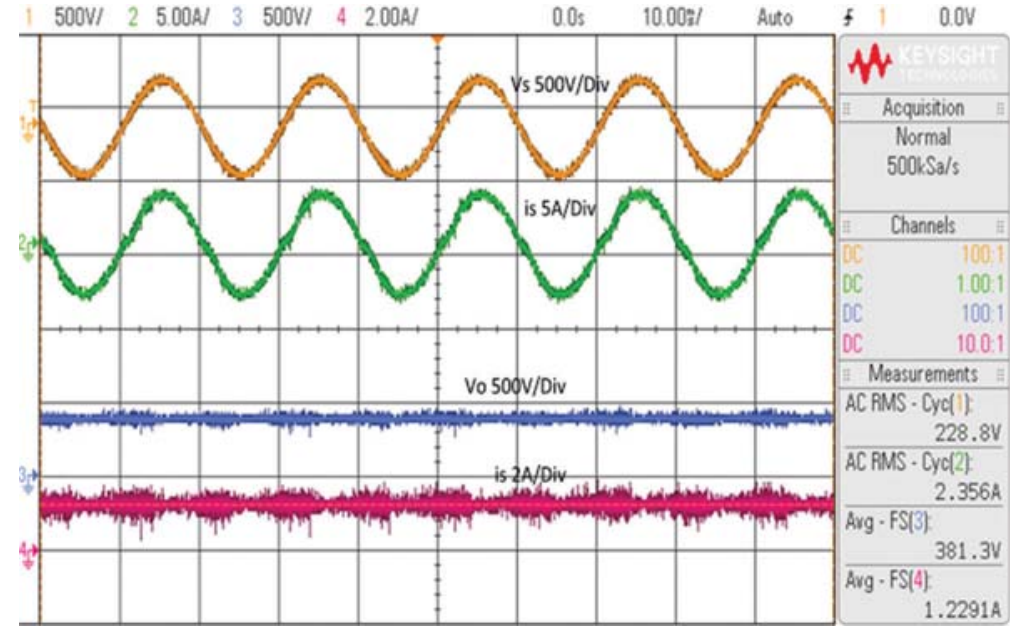

(i) Ch-1: $\mathrm{v}_{\mathrm{s}}(500 \mathrm{~V} / \mathrm{div})$, Ch-2: $\mathrm{i}_{\mathrm{s}}(5 \mathrm{~A} / \mathrm{div}), \mathrm{Ch}-3: \mathrm{v}_{\mathrm{o}}(500 \mathrm{~V} / \mathrm{div})$, Ch-4: $\mathrm{i}_{\mathrm{o}} 2 \mathrm{~A} / \mathrm{div}$

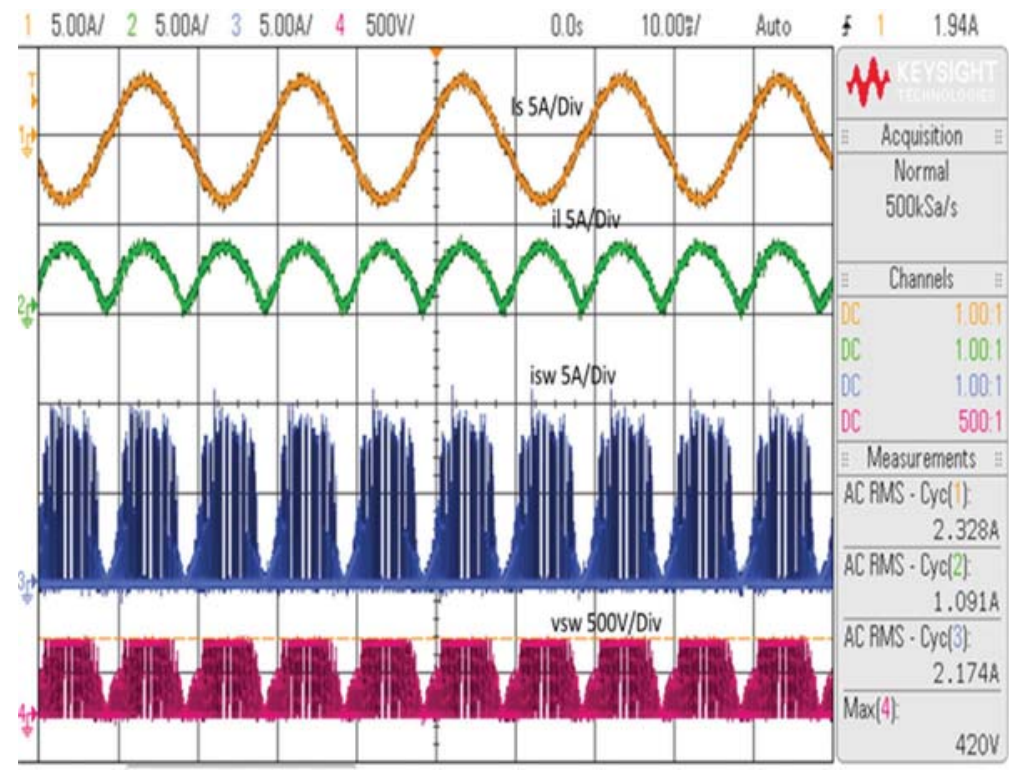

(ii) Ch-1: $i_{\mathrm{s}}(5 \mathrm{~A} / \mathrm{div}), \mathrm{Ch}-2: \mathrm{i}_{\mathrm{L}}(5 \mathrm{~A} / \mathrm{div}), \mathrm{Ch}-3: \mathrm{i}_{\mathrm{sw}}(5 \mathrm{~A} / \mathrm{div}), \mathrm{Ch}-4: \mathrm{v}_{\mathrm{sw}}(500 \mathrm{~V} / \mathrm{div})$

(b)

Figure 8 Steady state voltage and current waveforms of converter feeding $500 \mathrm{~W}$ load in constant voltage mode with different source voltage (a) $\mathrm{V}_{\mathrm{s}}=85 \mathrm{~V}$ (b) $\mathrm{V}_{\mathrm{s}}=230 \mathrm{~V}$. 


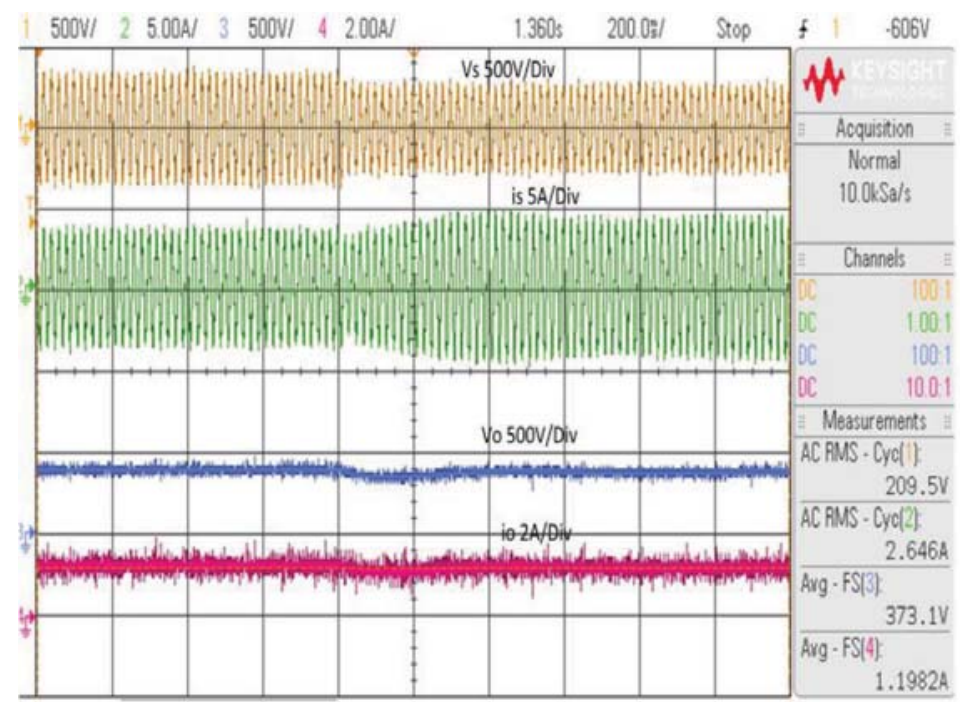

(a) Ch-1: $\mathrm{v}_{\mathrm{s}}(500 \mathrm{~V} / \mathrm{div}), \mathrm{Ch}-2: \mathrm{i}_{\mathrm{s}}(5 \mathrm{~A} / \mathrm{div}), \mathrm{Ch}-3: \mathrm{v}_{\mathrm{o}}(500 \mathrm{~V} / \mathrm{div}), \mathrm{Ch}-4: \mathrm{i}_{\mathrm{o}} 2 \mathrm{~A} / \mathrm{div}$

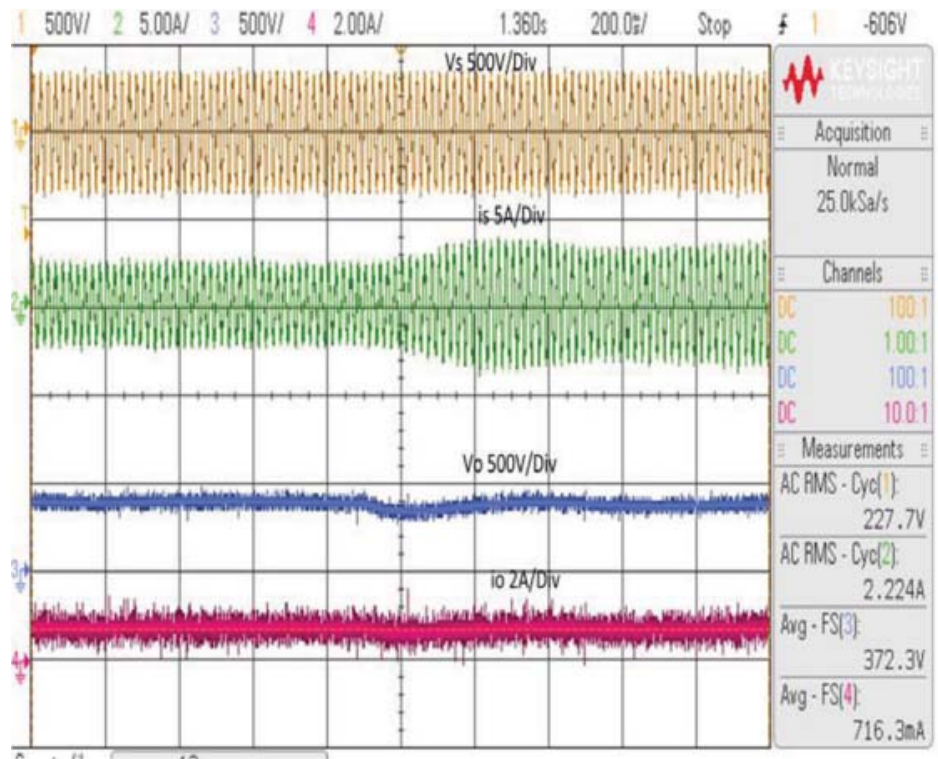

(b) Ch-1: $\mathrm{v}_{\mathrm{S}}(500 \mathrm{~V} / \mathrm{div}), \mathrm{Ch}-2: \mathrm{i}_{\mathrm{s}}(5 \mathrm{~A} / \mathrm{div}), \mathrm{Ch}-3: \mathrm{v}_{\mathrm{o}}(500 \mathrm{~V} / \mathrm{div}), \mathrm{Ch}-4: \mathrm{i}_{\mathrm{o}} 2 \mathrm{~A} / \mathrm{div}$ 


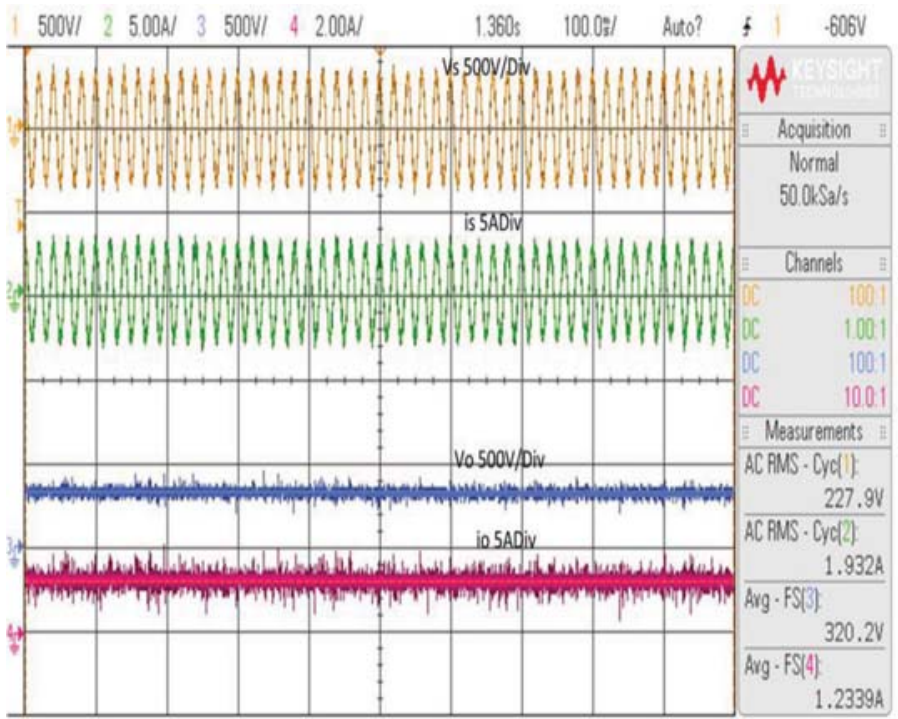

(c) Ch-1: $\mathrm{v}_{\mathrm{S}}(500 \mathrm{~V} / \mathrm{div}), \mathrm{Ch}-2: \mathrm{i}_{\mathrm{S}}(5 \mathrm{~A} / \mathrm{div}), \mathrm{Ch}-3: \mathrm{v}_{\mathrm{o}}(500 \mathrm{~V} / \mathrm{div}), \mathrm{Ch}-4: \mathrm{i}_{\mathrm{o}} 2 \mathrm{~A} / \mathrm{div}$

Figure 9 Performance of converter under (a) source disturbance from $230 \mathrm{~V}$ to $180 \mathrm{~V}$ (b) load disturbance from $300 \mathrm{~W}$ to $500 \mathrm{~W}$ (c) battery charging under constant current mode at $230 \mathrm{~V}$ input voltage.

maintained along with the sinusoidal shape of the source current waveform and unity displacement factor. Figure 9 shows the dynamic performance of the converter during supply voltage and load disturbances. During the supply voltage variation from $230 \mathrm{~V}$ to $180 \mathrm{~V}$ as shown in Figure 9a, the battery charging with $400 \mathrm{~V}$ (constant voltage mode) is maintained with a settling time of $300 \mathrm{msec}$ and permissible overshoot. During load disturbance, load is changed from $300 \mathrm{~W}$ to $500 \mathrm{~W}$ as shown in Figure $9 \mathrm{~b}$. In this case also the converter is stabilized with new load after a settling time of $300 \mathrm{msec}$. Figure $9 \mathrm{c}$ shows the steady state voltage and current waveforms with battery charging in constant current mode with $230 \mathrm{~V}$ as input voltage. In this case battery is charging with constant current of $1.25 \mathrm{~A}$ and output voltage is left unregulated.

Figure 10 shows the waveform of supply voltage $\left(\mathrm{v}_{\mathrm{s}}\right)$ and supply current $\left(\mathrm{i}_{\mathrm{S}}\right)$, input active power $\left(\mathrm{P}_{\mathrm{S}}\right)$ and reactive power $\left(\mathrm{Q}_{\mathrm{S}}\right)$ at input voltage of $85 \mathrm{~V}$ (min) and $230 \mathrm{~V}$ (nominal). With $85 \mathrm{~V}$ input voltage, it is observed that a voltage THD of $1 \%$ and current THD of $4.8 \%$ is obtained. At this time reactive power required is 50 VAR as shown in Figure 10b. With nominal voltage of 


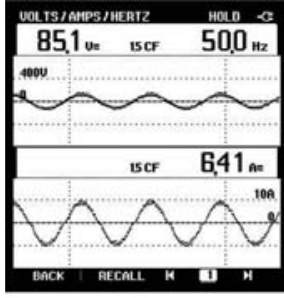

(a)

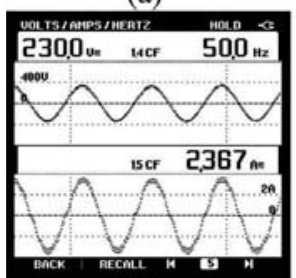

(e)

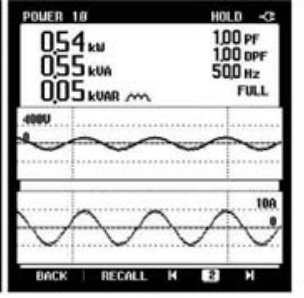

(b)

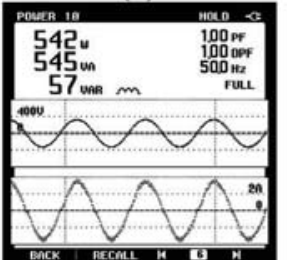

(f)

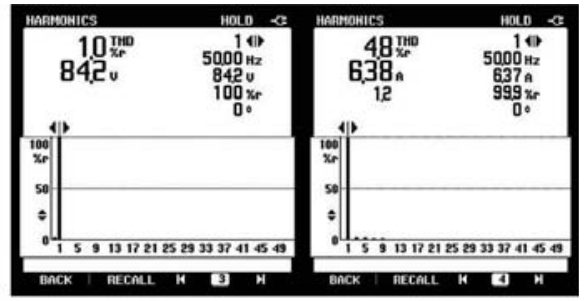

(c)

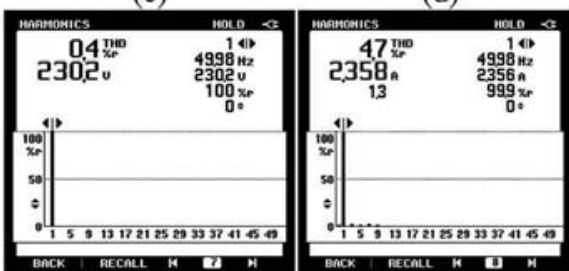

(g)

(h)

Figure 10 Power quality indices in terms of $v_{s}$ and $i_{s}, P_{s}$ and $Q_{s}$, Harmonic spectrum of $v_{s}$, Harmonic spectrum during charging battery load in CV Mode (a) to (d) at $85 \mathrm{~V}$ input, (e) to (h) at $230 \mathrm{~V}$ input.

$230 \mathrm{~V}$ as input source voltage to converter and delivering load of $500 \mathrm{~W}$ at constant voltage (CV) mode, Figure 10e, Figure 10g and Figure 10h show waveforms of source voltage, source current and its THDs which is $0.4 \%$ and $4.7 \%$ respectively. Table 2 shows power quality measures such as voltage distortion and current distortion along with power factor at different input voltage. During this time, the converter driving a load of $500 \mathrm{~W}$ with constant voltage in operation. Table 2 also gives the similar readings for constant current operation. The converter is made to operate at a constant output current of $1.25 \mathrm{~A}$. In both the modes of battery charging, performance of converter from power quality point of view is found satisfactory.

Table 2 Power Quality measures of battery charging with different supply voltages

\begin{tabular}{|c|c|c|c|c|c|c|}
\hline \multirow{3}{*}{$\begin{array}{c}\text { Supply } \\
\text { Voltage } \\
\left(V_{\mathrm{s}}\right)\end{array}$} & \multicolumn{6}{|c|}{ Methods of Battery Charging } \\
\hline & \multicolumn{3}{|c|}{ Constant Voltage $(\mathrm{CV})$} & \multicolumn{3}{|c|}{ Constant Current (CC) } \\
\hline & $V_{\mathrm{STHD}}$ & $I_{\mathrm{STHD}}$ & $\mathrm{PF}$ & $\overline{V_{\mathrm{STHD}}}$ & $I_{\mathrm{STHD}}$ & $\mathrm{PF}$ \\
\hline $85 \mathrm{~V}$ & $1.0 \%$ & $4.8 \%$ & 0.99 & $1.0 \%$ & $4.8 \%$ & 0.99 \\
\hline $120 \mathrm{~V}$ & $0.7 \%$ & $4.8 \%$ & 0.99 & $0.7 \%$ & $4.8 \%$ & 0.99 \\
\hline $150 \mathrm{~V}$ & $0.6 \%$ & $4.7 \%$ & 0.99 & $0.6 \%$ & $4.7 \%$ & 0.99 \\
\hline $200 \mathrm{~V}$ & $0.5 \%$ & $4.7 \%$ & 0.99 & $0.5 \%$ & $4.7 \%$ & 0.99 \\
\hline $230 \mathrm{~V}$ & $0.4 \%$ & $4.7 \%$ & 0.99 & $0.4 \%$ & $4.7 \%$ & 0.99 \\
\hline $265 \mathrm{~V}$ & $0.5 \%$ & $4.6 \%$ & 0.99 & $0.5 \%$ & $4.6 \%$ & 0.99 \\
\hline
\end{tabular}




\section{Comparative Analysis}

In order to highlight the benefits, a comparative study between the proposed PFC converter and buck-boost based improved power quality converters is carried out in view of switch voltage stress, current stress, conduction loss, switching loss and results are summarized in Table 3. The data is tabulated for these two configurations at a maximum duty-cycle corresponding to the minimum input voltage. The proposed topology has shown an improvement in efficiency, with reduced voltage stress and current stress of switch in comparison with buck boost topology based IPQC.

The comparison is done keeping the following parameters in view.

\subsection{Duty-Cycle Requirement}

The duty-cycle requirement of the proposed converter is much lower as compared with the conventional scheme. It is also shown that the switch current stress is less owing to the inherent topological voltage gain equation.

\subsection{Efficiency}

The switch voltage stress is lower compared to the conventional step-down based PFC converters with the additional advantage of reduced current stress. This results in reduced conduction loss as well as reduced switching loss resulting in improved efficiency which is shown in Table 3. It can be shown that both switching and conduction losses are less over the entire input voltage range compared to the conventional schemes resulting in increased efficiency. Typical $R_{\mathrm{dson}}$ is assumed to be $10 \mathrm{~m} \Omega$ and typical sum of rise and fall time is assumed to be $30 \mathrm{nsec}$, in calculating the conduction and switching loss

Table 3 Comparison between Conventional Buck-Boost based topology and Proposed Topology

\begin{tabular}{lcc}
\hline Topology & Buck-Boost based Topology & Proposed Topology \\
\hline Duty-cycle at 85 V Input & 0.76 & 0.4 \\
Switch Voltage stress & $520 \mathrm{~V}$ & $400 \mathrm{~V}$ \\
Switch Current Stress & $5.2 \mathrm{~A}$ & $1.664 \mathrm{~A}$ \\
Conduction Loss & $205 \mathrm{~mW}$ & $11 \mathrm{~mW}$ \\
Switching Loss & $0.21 \mathrm{~W}$ & $0.05 \mathrm{~W}$ \\
Reverse recovery loss & $86.6 I_{R R M} t_{B}$ & $66.66 I_{R R M} t_{B}$ \\
in diode & & \\
Turn-on loss in switch & $520\left(\left(I_{s w}+I_{R R M} / 2\right) t_{A}+\right.$ & $400\left(\left(I_{s w}+I_{R R M} / 2\right) t_{A}+\right.$ \\
due to diode recovery & $\left.\left(I_{R R M} / 3\right) t_{B}\right)$ & $\left.\left(I_{R R M} / 3\right) t_{B}\right)$ \\
\hline
\end{tabular}


of the switch. To calculate the reverse recovery loss in diode and switch turn on loss due to diode recovery, an equation is used which consists of $\mathrm{I}_{\text {rrm }}$, maximum recovery current of diode, $t_{\mathrm{A}}$, time between zero crossing of current and peak recovery current, $t_{\mathrm{B}}$, time between peak of reverse recovery current and time where the current falls to zero. The sum of $t_{A}$ and $t_{B}$ together is called reverse recovery time. For a typical values of these parameters, reverse recovery loss is 86.6 times a known constant in the conventional converter, where as it is 66.66 times a known constant in the proposed converter. The known constant is $I_{R R M} t_{B}$. Switch turn on losses due to diode recovery is, 520 times a known constant for the conventional buck boost converter, where as it is 400 times a known constant for the proposed converter. The known constant is $\left(\left(I_{L}+I_{R R M} / 2\right) t_{A}+\left(I_{R R M} / 3\right) t_{B}\right)$.

\section{Conclusion}

The Cuk-derived PFC converter is proposed for electric vehicle battery charging at higher voltage level. The design, analysis and real time implementation of converter rated at $500 \mathrm{~W}, 400 \mathrm{~V}$ are carried out for power factor correction with ac input voltage range ( $85 \mathrm{~V}$ to $265 \mathrm{~V}$ ). The results are obtained under different loading conditions and demonstrate that the proposed converter is able to provide regulated output dc voltage irrespective of ac mains and load variations. The power quality indices at ac side such as THD and power factor etc. are recorded/evaluated to observe power quality performance. The experimental results show satisfactory steady state and transient performance under load and source voltage disturbances. This converter is also employed for battery charging under constant current mode at $230 \mathrm{~V}, 50 \mathrm{~Hz}$ ac input voltage and its performances are observed. Therefore, it is well accepted for different applications requiring power at high output voltage and reduced current such as battery charging for electric vehicles/EHV.

\section{Appendix A}

Supply voltage: Single phase $230 \mathrm{~V}, 50 \mathrm{~Hz}$; Input inductance $5 \mathrm{mH}$; Intermediate Capacitors $0.1 \mathrm{uF}$; Output capacitor $2200 \mu \mathrm{F}$; Switching Frequency $5 \mathrm{kHz}$; Gains of PI controller $\mathrm{k}_{\mathrm{p}}=100, \mathrm{k}_{\mathrm{i}}=10$ for constant voltage mode operation and $\mathrm{k}_{\mathrm{p}}=0.005$ and $\mathrm{k}_{\mathrm{i}}=10$, for constant current mode operation. 


\section{Appendix B}

Supply voltage: Single phase $230 \mathrm{~V}, 50 \mathrm{~Hz}$; Input inductance $10 \mathrm{mH}$; Intermediate capacitors $0.7 \mathrm{uF}$; Output capacitor $5000 \mu \mathrm{F}$; Switching Frequency $5 \mathrm{kHz}$; Gains of PI controller $\mathrm{k}_{\mathrm{p}}=15, \mathrm{k}_{\mathrm{i}}=10$ for constant voltage mode operation and $\mathrm{k}_{\mathrm{p}}=15$ and $\mathrm{k}_{\mathrm{i}}=10$ for constant current mode operation.

\section{References}

[1] Singh, B., Chandra, A., Al-Haddad, K., Pandey, A., and Kothari, D. (2003). A review of single-phase improved power quality ac-dc converters. IEEE Trans. Ind. Electron. 50, 962-981.

[2] Singh, B., Singh, S., Chandra, A., and Al-Haddad, K. (2011). Comprehensive study of single-phase ac-dc power factor corrected converters with high-frequency isolation. IEEE Trans. Ind. Inf. 7, 540-556.

[3] Bist, V., and Singh, B. (2015). PFC Cuk converter-fed BLDC motor drive. IEEE Trans. Power Electron. 30, 871-887.

[4] Wei, H., and Batarseh, I. (1998). "Comparison of basic converter topologies for power factor correction," in Proceedings of the IEEE South-East-Conference, Orlando, FL, 348-353.

[5] Pan, C. T., Lai, C. M., Cheng, M. C., and Hsu, L. T. (2009). "A low switch voltage stress interleaved boost converter for power factor correction," in Proceedings of the International Conference on Power Electronics and Drive Systems, Taipei, 49-54.

[6] Wai, R. J., Liu, L. W., and Duan, R. Y. (2005). High-efficiency voltageclamped dc-dc converter with reduced reverse-recovery current and switch-voltage stress. IEEE Trans. Ind. Electron. 53, 272-280.

[7] Das, P., Laan, B., Mousavi, S. A., and Moschopoulos, G. (2009). A Nonisolated bidirectional ZVS-PWM active clamped DC-DC converter. IEEE Trans. Power Electron. 24, 553-558.

[8] Wu, T. F., Lai, Y. S., Hung, J. C., and Chen, Y. M. (2008). Boost converter with coupled inductors and buck boost type of active clamp. IEEE Trans. Ind. Electron. 55, 154-162.

[9] Wai, R. J., Wang, W. H., and Lin, C. Y. (2008). High-performance standalone photovoltaic generation system. IEEE Trans. Ind. Electron. 55, 240-250. 
[10] Wai, R. J., Lin, C. Y., Duan, R. Y., and Chang, Y. R. (2008). Highefficiency power conversion system for kilowatt-level stand-alone generation unit with low input voltage. IEEE Trans. Ind. Electron. 55, 3702-3714.

[11] Wang, C. M., Lin, C. H., Yang, T.-C., and Lin, H.-Y. (2010). "Analysis and design of high performance voltage-doubler rectifier," in Proceedings of the 5th IEEE Conference on Industrial Electronics and Applications, Taichung, 1124-1129.

[12] Jang, Y., and Jovanovic, M. (2007). Interleaved boost converter with intrinsic voltage-doubler characteristic for universal-line PFC front end. IEEE Trans. Power Electron. 22, 1394-1401.

[13] Axelrod, B., Berkovich, Y., and Ioinovici, A. (2005). Hybrid switchedcapacitor-cuk/zeta/sepic converters in step-up mode," in Proceedings of the IEEE International Symposium on Circuits and Systems, Kobe, $1310-1313$.

[14] Ismail, E., Al-Safar, M., Sabzali, A., and Fardoun, A., (2008). A family of single-switch PWM converters with high step-up conversion ratio. IEEE Trans. Circ. Syst. I 55, 1159-1171.

[15] Valsera Naranjo, E., Sumper, A., Lloret-Gallego, P., Villafafila Robles, R., and Sudria Andreu, A. (2009). "Electrical vehicles: state of art and issues for their connection to the network," in Proceedings of 10th International Conference on Electrical Power Quality and Utilization, Lodz, 1-3.

[16] Putrus, G. A., Suwanapingkarl, P., Johnston, D., Bentley, E. C., and Narayana, M. (2009). "Impact of electric vehicles on power distribution networks," in Proceedings of the IEEE Vehicle Power and Propulsion Conference, Dearborn, MI, 827-831.

[17] Ul-Haq, A., Cecati, C., Strunz, K., and Abbasi, E. (2015). Impact of electric vehicle charging on voltage unbalance in an urban distribution network. J. Intell. Ind. Syst. 1, 51-60. 


\section{Biographies}

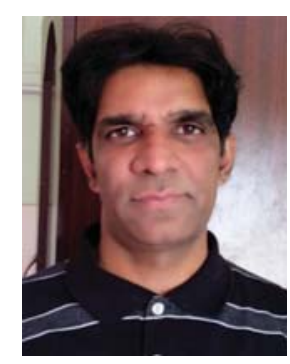

B. R.Ananthapadmanabha received the B.E. degree in electrical engineering from R. V. College of Engineering, Bangalore, India, in 1993, the M.Tech. degree in electrical engineering with a specialization in power electronics from the B. M. S. College of Engineering, Bangalore, India, in 2005, and is currently pursuing Ph.D. degree in Electrical Engineering at Sardar Vallabhbhai National Institute of Technology, Surat, Gujarat, India. In 2005, he joined Hynetic electronics, Bangalore as field application engineer working in the area of dc/dc converters, battery chargers. In 2011 he joined Incap CMS 1td., Bangalore as Project manager for the product management of UPS, inverters. His fields of interest include power electronics, power quality, and design of dc/dc Converters.

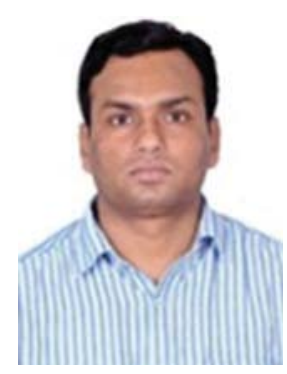

Rakesh Maurya received B.Tech. in Electrical Engineering from the Kamla Nehru Institute of Technology Sultanpur, Uttar Pradesh in 1998 and M.Tech. (Power Electronics and Electric Drive) and Ph.D. in Electrical Engineering from Indian Institute of Technology Roorkee, India in 2002 and 2014 respectively. Presently, he is serving as faculty member in the department of 
Electrical Engineering, Sardar Vallabhbhai National Institute of Technology Surat, Gujarat, India. His fields of interest include design of Switching Power Converters, High power factor AC/DC Converters, hybrid output converter, Power quality problems, Advanced Electric drives and applications of Real Time Simulator for the control of power converters. He is a Member of the Institute of Electrical and Electronics Engineers (IEEE) and Life member of System Society of India (SSI).

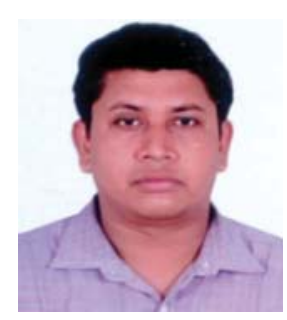

Sabha Raj Arya received Bachelor of Engineering (Electrical Engineering) degree from Government Engineering College Jabalpur, in 2002, Master of Technology (Power Electronics) from Motilal National Institute of Technology, Allahabad, in 2004 and Ph.D. degree from Indian Institute of Technology (I.I.T.) Delhi, New Delhi, India, in 2014. He is joined as Assistant Professor, Department of Electrical Engineering, Sardar Vallabhbhai National Institute of Technology, Surat. His fields of interest include power quality, power factor correction converter, design of power filters and distributed power generation.

He received Two National Awards namely INAE Young Engineer Award from Indian National Academy of Engineering, POSOCO Power System Award from Power Grid Corporation of India in the year of 2014 for his research work. He is also received Amit Garg Memorial Research Award2014 from I.I.T. Delhi from the high impact publication in a quality journal during the session 2013-2014. He is a Senior Member of the Institute of Electrical and Electronics Engineers (IEEE). 


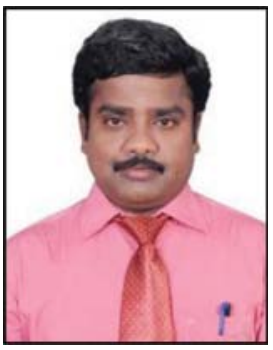

B. Chitti Babu received the Ph.D. in Electrical Engineering from National Institute of Technology Rourkela, India in 2012. He had been with National Institute of Technology Rourkela, India as an Assistant Professor in Electrical engineering department from 2007 to 2013. Subsequently He had two post-doc research appointments with Wroclaw University of Science \& Technology, Poland from December 2013-June 2014 and VSB-Technical University of Ostrava, Czech Republic from September 2014 to September 2015 and both the appointments have been sponsored by European Commission, U.K. He was a visiting researcher with the Department of Electronics, Information and Bioengineering, Polytechnic University of Milan, Italy from December 2014 to February 2015. In September 2016, he was appointed as an Assistant Professor in the department of electrical \& electronics engineering, The University of Nottingham Malaysia Campus, Malaysia. His research interests include power electronics applications in smart distribution grid containing renewable energy sources and low-power electronics design, including photovoltaic energy systems. He is a senior member of IEEE, IEEE Smart Grid Community, and IEEE Power \& Energy Society. 
